\title{
TECHNOLOGICAL ADVANCEMENT AND CHILD-FRIENDLY EDUCATION IN NIGERIA: A POST-COVID REVIEW
}

\author{
Esther Ololade Adekunle ${ }^{1}$, Olawale Yinusa Olonade ${ }^{2 \star}$, Olaniyi Trust Ayodele ${ }^{3}$, Tayo \\ Ola George ${ }^{4}$, \\ ${ }^{1}$ Department of Political Science and International Relations, Covenant University, Ota, Nigeria \\ ${ }^{2}$ Department of Sociology, Covenant University, Ota, Nigeria, \\ olawale.olonade@covenantuniversity.edu.ng \\ ${ }^{3}$ Department of Political Science and International Relations, Covenant University, Ota, Nigeria \\ ${ }^{4}$ Department of Sociology, Covenant University, Ota, Nigeria \\ ${ }^{*}$ Corresponding Author
}

\begin{abstract}
Over the years, education has been a source of sustainable development in many countries in the world. Unfortunately, even though it is a potent weapon for measuring a country's development, it has suffered setbacks resulting in poor quality education. Quality Education is a significant prerequisite for developing every country's one of the United Nations' sustainable development goals. According to the United Nations, every child is entitled to quality and accessible education equipped with skills useful for their future development. For a child to enjoy quality education regarding the United Nations Sustainable Development Goals, technology is necessary. Technology in education has helped solve many problems, making lifelearning processes enjoyable and exciting for every child to learn. The adoption of technology in education comes with many advantages embedded in improving communication and research. However, some challenges have affected easy access to learning, which has led to low participation in educational activities. This study embraces the Modernization theory, which talks about the description and explanation of transformation processes from a simple traditional society to a more complex modern society in all spheres of life. Hence, this paper seeks to examine the challenges and impacts of technological advancement in education in Nigeria.
\end{abstract}

Keywords: Technology, Education, Child friendly, Sustainable Development, UNESCO, UNICEF

\section{INTRODUCTION}

As affirmed by the former South African president, Nelson Mandela, education remains the most potent instrument needed to transform every human society. Regarding the 17 United Nations Sustainable Development Goals (SDGs), access to quality education is the fourth goal: to ensure an equitable and inclusive education and promote lifelong learning opportunities. Benefits of qualitative education are 
countless, including the openings of job opportunities, developing a career path, increased wages, access to good health, and maximum fulfillment in life (Fagbohun, George, Onwumah, Olonade, and Aderoju, 2018). With education also comes economic empowerment. Amory (2012) noted that a positive and strong relationship exists between the average number of years in school and the GDP of a nation.

The COVID-19 pandemic has also aggravated the challenges of access to education globally, with more than 1.5 billion students in 188 nations, representing more than 91 percent of the global population of students forced out of school by April 2020 (UNESCO, 2020). The pandemic exposed many weaknesses in many nations of the world, mostly African countries leading to inadequate or late response among the education stakeholders regarding the accessibility of the internet for school children and learning materials. Several school children in many African countries are confronted with the COVID-19 pandemic consequence, including limited access or lack of education, with many dropping further than their peers. As posited by Baporikar (2016), the sense of normalcy and stability provided by schools will also elude students affected by the closure of schools.

Schools' closures have affected many students and school-children who do not have access to education or are highly prone to exclude inclusive and accessible education on different circumstances. These include children with disabilities, students in rural or underdeveloped areas, asylum seekers, and refugees, including the families that experienced job insecurity, losing their jobs in this crucial period, and a difficult situation. Many school-children from low-income nations rely heavily on government school feeding programs and critical information and health services. About 50 percent of the global school-children, which is around 310 million, relied on school for daily food, with 48 million school-children in Brazil, 100 million in India, and 9 million each in South Africa and Nigeria (Delmater, 2004).

UNESCO's recommendation emphasizes the need for nations to embrace no-tech, low-tech, and hi-tech solutions to enable learning continuity. Although the online learning platform has gained much attention, several governments owned schools are not equipped to embrace them and lack the technology to do online teaching. In China, it was observed that some students had to hike to search for signals to participate in online classes on mountaintops (Dangwal \& Gope, 2011).

However, educational guidelines targeted at learning online during the coronavirus pandemic have increased existing inequalities. School-children residing in deserted places in the world mostly experience the challenges of poor internet connection at an unaffordable cost, perhaps for those who can access the internet. Not only that, countries like India, Myanmar, and Bangladesh have sealed the hope of accessing online classes due to their policy on internet shutdowns (Olivier, 2014).

Thus, the urgent shift to online classes also points out the need for data privacy considerations for children. Observations in many countries have shown that Children's education data protection is far less than health data. Most nations have rules guiding the disclosure and appropriate uses of individually recognizable health data, including emergencies. Nevertheless, whereas there is a high level of sensitivity to school-children data with the capacity to reveal their names, behaviors, home addresses, and other classified individual information, which, when misused, can harm children and families, many nations lack data privacy policy for the protection of children. The implication of this is that governments have to make efforts to take care of those handling Educational Tech (ET) and make them accountable for handling these children (Olivier, 2013).

The idea that information and technology can change the educational landscape has opened up new opportunities and attracts global interest. New digital products and services are pilot, develop, and scale-up in the educational sector by various development bodies, commercial software and hardware producers, and educational institutions. Courtesy of ICT, access to high-quality educational content, including video materials, textbooks, and remote instruction, is increased at a very affordable price compared to the preCOVID period. These technologies can maximally enhance students' motivation by making learning more exciting and applicable. Furthermore, possibilities are created for personal engagement in educational activities, help learners study based on their abilities, and help teachers (Kerr, 2005).

Digital technology has provided platforms for learning opportunities for school-children worldwide, particularly children in remote places. It has promoted the right level of participation towards online learning among children and accesses a wide variety of informative and educational content, which was inaccessible to earlier generations of children (Delmater, 2004).

\section{CONCEPTUAL CLARIFICATIONS}

Studies conducted by the Agence Universitaire de la Francophonie (AUF), UNESCO, the French 
Development Agency (AFD), and Orange show that mobile learning and ICT promotes many benefits. These benefits include more value than the traditional teaching method, complimentary teacher training solution, and access to low-cost teaching resources. The import of these is the vast possibility to reach those who have been excluded from the educational system.

Technological advances, skills, and information spread rapidly and have shaped people's lives (Einar, 2006). The internet is a form of Child-centered that encourages participation, creativity, self-technology, and information advancement. It also stands for interconnected networking. According to the internet, the curriculum structure and learning methods are a global computer network that connects millions of development, abilities, and learning styles of computers throughout the World (Juharis, Rasul, 2008); and consider the needs of children above others. The internet can be interpreted as large global actors in the educational system.

\section{ICT IN EDUCATION IN SUB-SAHARAN AFRICA}

Schooling is a significant aspect of human life. In determining the level of ICT in quality education, there are limitations; an example is an inadequacy in data gathering in Sub-Saharan Africa. However, many countries necessarily do not engage in systematic information gathering though few others are still coming up with initiatives, despite the modern data survey carried out by these countries such as the Democratic Republic of Congo, Benin, Angola, the Central African Republic, Somalia, and Djibouti. It was discovered that no data survey or gathering was collected regarding ICT on education, which was present at the national level. National priorities are usually shown by the existence of a scientific data collection.

Nevertheless, countries in developing nations have challenges incorporating ICT, which is of everyday necessity, unlike intentions vital, thereby including increment in enrollment rates, a decrease in the population of children unable to attend school, and ensuring an adequate number of trained teachers. Also, the introduction of ICT in education is rapidly growing in many countries due to improved government policy, financial resources, basic amenities, and well-equipped teachers.

For instance, in the Gambia, mostly in tertiary institutions, facilities like computer laboratories were set up with a fast internet connection by the Government of Taiwan in partnership with the Gambian government, currently working for the university at large alongside the private-sector groups. Moreover, a few laboratories are connected to the internet at the Gambia Technical Training Institute (GTTI). At the post-primary level, the Ministry of Education has provided computer laboratories for all state schools. For instance, about 16 state secondary schools (out of 31) have been equipped with networked computer facilities highly useful.

In Cape Verde, through the Education and Sports Ministry, adequate budgetary provisions were made for financial assistance. As part of overall reform, the country has developed a strategic plan for ICT in education. Cape Verde has ensured 4000 digital devices for students at an estimated cost of 280,000 Euros. The Government of Cape Verde has taken responsibility in financing this effort and school connectivity but is still liaising with the United Nations and World Bank financing for more equipment and technology in schools (Tobor, 2018).

\section{ICT IN NIGERIA AND THE COVID-19 PANDEMIC}

The international system is not static but evolving. Moreover, technology is changing human activities rapidly. These changes include the challenges that the human race is facing, making our educational system fragile and weak, such as the current problem of the COVID-19 pandemic. For instance, the pandemic has exposed the weakness in teaching and learning in Nigerian schools because the teaching paradigm's nature fails. In Nigeria, the country's current lockdown, coupled with the COVID-19 pandemic, is severely impacting science education. The advent of Coronavirus (COVID-19) in Nigeria has dealt a severe blow to its education in 2020. The pandemic's effect is alarming in the nation's educational system (Sahu, 2020). The government shut down all schools in the nation and clamored for social distancing to curtail the virus's spread. The COVID-19 pandemic period is a good example, such that when the old patterned teaching paradigm could not work in schools. It was a period of enforcing social distancing whereby students and teachers are not allowed to interact physically. Schools are closed down for many months; thus, teaching and learning are disrupted (UNESCO, 2020). Teaching and learning in science required interactions between students and the teachers, which may be physical (Akhtar, Hussain, Afzal \& Gilani, 2019). Therefore, students staying away from schools for an extended period may adversely impact their academic performance. Therefore, the Nigerian government must be more committed to e-learning in our tertiary institutions and other education levels. Although e-learning is not new in the Nigerian educational system, the quality and effectiveness are critical. One of the learning frameworks that enables students to connect with the teacher 
to learn outside the school context is Google classroom. Secondly is the classification of e-learning as computer-based and internet-based (Arkorful \& Abaidoo, 2014).

The type depends on the user mode. The computer-based involves the use of ICT, while the internet-based is purely online. The computer-based includes computer software and hardware (Algahtani, 2011); the internet-based comprises Email, blog, and other references (Almosa in Arkorful \& Abaidoo, 2014). Based on the above, the classification can be done via the idea of online and blended learning. Blended learning has several definitions depending on scholars' intellectual persuasion. Cleveland-Innes and Wilton (2018) categorized blended learning into three blended interaction and presentation, blended block, and entirely online. Some tools are peculiar to e-learning for effectiveness, depending on the types. According to Pande, Wadhai, and Thakare (2016), Weblog, Social bookmarking, Wiki, RSS, Podcasting, Instant messaging, Text chat, and internet forums are essential tools for any e-learning. The benefits of e-learning are enormous. Some of the advantages, according to Pande, Wadhai, and Thakare (2016), include flexibility, efficiency in knowledge and qualification enhancement, the motivation of students' interaction, cost-effective, and others. Despite the vital roles e-learning plays in tertiary education in many countries of the world: most developing nations, including Nigeria, are yet to unlock the full potentials of it (Kyari, Adiuku-Brown, Abechi, Pyochi \& Adelakun, 2018). Online learning aims at shifting the educational environment's attention away from the face-to-face classroom context for knowledge dissemination (Franklin \& Nahari, 2018). The e-learning in some parts of the globe is not a recent development in promoting education; Nigeria schools are using it to promote lifelong learning and distance education (Ajadi, Salawu \& Adeoye, 2008). Several studies had been documented on e-learning, how students receive instructions from teachers, and learn adequately at all times, including the vacation period (Zare, Sarikhani, Salari \& Mansouri, 2016; Franklin \& Nahari, 2018; Aina \& Olanipekun, 2018). An exploration of different types of e-learning is possible as practiced in most developed nations. The typical e-learning in most Nigerian universities is the distance learning program. There are concerns about how the distance learning program could effectively teach online students by exploiting ICT technologies and collaboration to enhance in-depth interactive engagement (Magen-Nagar \& Shonfeld, 2017). Some devices used for this distance learning program are televisions, CD-ROM, and Radio (Kyari, Adiuku-Brown, Abechi \& Adelakun, 2018) and mobile phones (Aina \& Olanipekun, 2018). E-learning is critical to higher education as it helps with the use of information and communication technologies in various education processes to support and enhance learning (Pande, Wadhai \& Thakare, 2016). Therefore, to mitigate the impacts of the coronavirus pandemic on the learning of science education in higher education required the adoption of e-learning during the period of lockdown. However, due to the rule of social distancing, any e-learning that requires physical contact during teaching and learning may not be effective. Given this, any of the blended learning may not be the best for science education at this period except for the full online mode. Therefore, doing an extensive literature search shows that the best e-learning suitable for teaching and learning at this period could be the Google Classroom.

Google Application for Education helps teachers organize and create assignments quickly, provide efficient feedback, and easily communicate with their learners (Shaharanee, Jamil \& Rodzi, 2016). The application has been used as e-learning (Henukh, Rosdianto \& Oikawa, 2020). Research studies indicate that the application helps students learn more electronically and teachers spend more time with students than with papers (Basher, 2017; Rabbi, Zakaria \& Tonmoy, 2018). Google classroom is an emerging technology in education since 2014, which had impacted teaching and learning in most developed and developing nations (Shaharanee, Jamil \& Rodzi, 2016; Basher, 2017; Rabbi, Zakaria \& Tonmoy, 2018; Henukh, Rosdianto \& Oikawa, 2020). Previous studies show that google classrooms enhance ongoing learning because both the teachers and the students can be cited in various geographical contexts (Mafa, 2018; Henukh \& Rosdianto, Oikawa, 2020). Previous studies have suggested that e-learning has challenges that could make them unsuitable at this period of COVID-19. The inadequacy of Nigeria's weak and underdeveloped infrastructure is a significant shortcoming (Trucano, 2014)). For Mohamedbhai (2014), inequalities could be one problem of distance e-learning because of the differences between urban and rural students; between the rich and the poor who cannot afford the internet's cost. For Ajadi, Salawu, and Adeoye (2008), bandwidth and diversion of intention on the net are some of the problems associated with e-learning. Earlier studies show that Google Classroom enhances learning because it can use it in different geographical locations (Mafa, 2018; Henukh \& Rosdianto, Oikawa, 2020). Google Classroom, launched less than a decade ago, has been one of the compelling ways technology impacts teaching and learning in the World (Azhar \& lqbal, 2018). Given the above, it is apparent that one way to mitigate the impacts of the coronavirus disease on science education may be to adopt an e-learning model to teach science in Nigeria higher institutions.

\section{CHALLENGES OF ICT IN EDUCATIONAL INSTITUTIONS}

Scholars like Ilaonisi and Osuawgwu (2010) have explained that there are factors hindering ICT use in an 
educational setting in the country. Many of them include inadequate ICT facilities, limited funds allocated to technology, high cost of ownership, and cost of the consumer and policy implications of the disparity by ICT technology's capabilities and the aims of individual educational institutions.

Poor ICT Infrastructure is a big problem in education. In many schools or colleges, society, and the environment, access to connection universally is poor. Therefore, quite a level of progress has been made in this regard. This, however, calls for an urgent need to destroy those barriers hindering the development of tertiary institutions in Nigeria. Education that involves the use of web or connection is heavily reliant on more robust internet connectivity. This type of education, also known as web-based education, could be done via online, mobile, or distance learning in many of these institutions. Unfortunately, this is possible if there is adequate funding from the public and private sectors.

Human capital flight is the main problem obstructing the development of any country. It depletes every resource's potential in a given territory in aspects like education, telecommunication and technology, research, and development. This challenge has led to inadequacy and docility in many scientists and socalled experts, making them irrelevant in the ICT sector. More so, the absence of a friendly and conducive environment on encouraging the implementation of strategies by policy-makers would have encouraged these scientists and government policies.

However, according to Insightful et al. (2003), some other challenges were drafted. These include:

- Unaffordable running internet costs by consumers

- Absence of awareness and motivation to attract potential users

- Identification of information sources that meet the needs of users

- Low Quality of Service of the internet and telecommunication services

- Improper management of network congestion.

\section{METHODOLOGY}

This study adopts a qualitative design that involved the use of non-statistical methods. It also involves using secondary data such as journals, online sources and websites, scholarly publications, books, and other journals' empirical facts.

\section{DISCUSSION OF FINDINGS}

A significant problem of how ICT can promote and encourage the value of education, especially in African countries, has been a thing of concern. From many studies, education quality, especially in African countries, is very alarming and discouraging. However, the studies have revealed various interests from diverse backgrounds seeking education through technological advancement in the educational sector as an arising topic. (Mitra, 2003; Selinger, 2009; Isaac and Hollow, 2012). Nevertheless, it has been observed that putting importance on the use of hardware in colleges is most likely to cause no or little improvement in the standard of quality in education for children. Many arguments have arisen concerning the use of technology in education on the broader community. For instance, there are differences between interferences that enhance a good education that improves educational outcomes (Hollow et al. 2012). Also, ICTs help in playing different roles in improving whether formal or informal education. It was revealed that girl enrolment is achievable under the use of technology in education because it gives easy access to greater participation among females in academic activities. Many vital research plans are evolving, which would help promote education for vulnerable and non-inclusive children (Bomal Nkansah 2010, Larsson et al. 2010). Moreover, ICTs can promote indigenous languages through bespoke, easy-to-use educational software for children (Azi, 2006).

Be that as it may, so much emphasis has been placed on the benefits of information and technology in schooling processes, which will be advantageous for all children. (Negroponte 2009) (Dangwal \& Gope, 2011 (Wintz, 2009). Despite teaching, the study has shown that, if working with teachers, introducing technology is vital in promoting sustainable development regarding quality education. Thus, tutors' significant challenges in utilizing new technology are lack of time available, lack of appropriate course content, and technical malfunction (Wan Zah Wan Ali 2009).

Hence, African nations are still committed to improving children's basic needs, such as good education, yet much work is yet to be accomplished. In the sub-Saharan region in Africa, it was estimated that 32 million children could not attend a school or have access to education at the primary school level. At the post- 
primary school level, estimates of about 26 million children are unable to go to school. Thus, a more excellent means of curbing this is through information and technology in schools.

Nevertheless, the value placed on technology in education cannot be undermined in educational institutions, which have been the impact of technology in educational institutions that have been examined for many years by studies in education. It has proven that technology can assist in various educational processes (Brown 2012, Dermentzi et al. 2016, Hung and Yyen 2010), have a long-lasting effect on student performances (Dyson et al. 2015), and help teachers toward professional advancement and development (Manca and Raineri 2017; Donelan 2016). Therefore, integrating technology into the classroom has been widely promoted globally (Cope \& Ward, 2002). The development of information and communications technology (ICT) and its schooling operation have helped learners become more opened and teaching methods more flexible, making students more reliant and determined, thereby equipping them with responsibility skills and learning (Goode et al. 2007). Such prospects also allow teachers to promote active learning so that learning is engaging and effective (Collis 1998), which makes them facilitators of the educational processes (Wiki 2019; Huang et al. 2020 (Goode 2007). Moreover, with the upsurge in technology, the child-centered approach is the central aspect of learning with flexibility because it empowers both the students and teachers to communicate in an informative way to one other (Lundin, 1999).

\section{SUMMARY OF FINDINGS}

Be that as it may, through the flow of information in education that technology has enabled, we see the teacher's role moving to a lesser stressful activity in many classrooms. Students take more responsibility for their learning using technology to gather necessary information.

Thus, technology is a powerful tool that can support and transform education in many ways. For instance, it helps make teaching easier for teachers to create instructional materials to create new ways for people to learn and be unified. With the use and reach of network universally in the educational sector, it will be better if instructional and educational technologies embrace the opportunity provided by technology to transform education to make education enjoyable and accessible for every child in Nigeria and all over the world. The usage of technology in online education creates an atmosphere where students can take responsibility for their participation in learning and equipping them with necessary life skills for the future rather than just going through schools' walls.

In conclusion, technological advancement in education is a global concern universally and is an issue perceived as an opportunity and, at the same time, vital. Many issues have been entangled by the use of technology in education. Hence, the future of technology in education is also about reforming education by establishing conducive and lasting learning. E-learning is a gateway to ensuring a knowledge-driven society that will result in sustainable development. In the future, students will incorporate so much independence into their learning process that mentoring will become fundamental to student success. The future of technology in education is taking new dimensions and realities of life in the evolving world, giving students opportunities to choose their learning way, combining theory and practice, always considering the market's current demand.

\section{RECOMMENDATIONS}

Firstly, information and technology in education should be highly appreciated and encouraged by private individuals and government agencies in the sub-region. By so doing, students will be motivated to feel free to learn through e-learning.

Secondly, an enabling environment should be provided for every child to participate in the learning processes. Not only for students but teaching processes should be carried out online also.

Then, in West- Africa, Nigeria is well known for its education capability, which is a suitable remark, but there is a need for more collaboration to strengthen ties. Therefore, education breeds development in a country with a good education and more vital collaboration.

\section{ACKNOWLEDGMENT}

The authors appreciate the immense contributions of Covenant University Center for Research Innovation and Discovery (CUCRID) to research endeavors and payment of this manuscript's article processing charges. 


\section{REFERENCE LIST}

AAUW Education Foundation (October 14, 1998). Technology Gender Gap Develops White Gaps in Mathematics and Science Narrow AAUW Foundation Report Shows. Retrieved April 23, 2011, from http://www.aauw.org/2000/ggpr.html

Aggarwal, A. (2000). Web-Based Learning and Teaching Technologies: Opportunities and Challenges. London; Idea Group Publishing.

Allenby. B.R. \& Sarew, D, (2011). The techno-human condition, The MIT Press, Cambridge.

Amory, A., 2012, 'Instructivist ideology: Education technology embracing the past?', Interactive Learning Environments 20(1), 41-55. https://doi.org/10.1080/ 10494821003714707

Ascough, R.S., 2002, 'Designing online distance education: Putting Pedagogy before technology,' Teaching Theology and Religion 5(1), 17-29. https://doi.org/ 10.1111/1467-9647.00114

Baporikar, N. (2016) 'Technology integration and innovation during reflective teaching,' International Journal of Information and Communication Technology Education 12(2), 14-22.

Bosch, A. (2002). Interactive Radio Instruction for Mathematics: Applications and Adoptions fromAroundtheWorld.RetrievedApril23,2011,fromhttp//www.techknow1ogiaorg/TKL_activepages2/Cur eentArticles $/$ main.asp?FileType $=H T M L \& A r t i c l e I D=255$

Cisler, S. (2002). Planning for Sustainability: How to keep your ICT Project Running. Retrieved April 23, 2011, from http//www.cid.harvard.edu/c r/pdf/gitrr2 002_chO4 pdf

Delmater, S. (2004). 'A typology of the use of technology in theological education', Teaching Theology and Religion 7(3), 134-140.

Fouts, J. (2002). Research on computers and Education: Past, Present, and Future. Retrieved April 23, 2019, from http://www.gatesfoundation.org/nr/down1oads/ed/evaluation/Computer Research Sumarry.pdf

Haddad, WAD. \& Draxier, A. (2002). "The Dynamics of Technologies for Education."In W.D. Haddad \& A. Drexler (Ms.).Technologies for Education: Potentials, Parameters, and Prospects (Washington DC: Academy for Educational Development and Paris: UNESCO.

Hannafin, R.D. \& Savenye, S. (1993). Technology in the Classroom: The Teacher's New Role and Resistance to it. Educational Technology, pg 26-31.

Hawkins, R. (2002). "Ten Lessons for ICT and education in the developing world. Retrieved April 23, 2011, from http://www.cid.harvard.edu/cr/pdf/gitrr2002c_104.pdf

Hernes, G. (2002). "Emerging Trends in ICT and Challenges to Educational Planning" In W.D. Haddad, \& A. Drexler (Eds.), Technologies for Education: Potentials, Parameters, and Prospects (Washington DC: Academy for Educational Development and Paris: UNESCO), p.25.http://ctn.fcoe.k12.ca.us/ctap/dhs3.4/tc02class.pdf,http://www.enlaceguiche.org/english/vision.ht $\mathrm{ml}$.

Hollow, D. Mitchell, J. \& Gladwell, C. (2012). Save the Children Vodafone research. London: Jigsaw Consult.

Iloanusi, NO. \& Osuagwu, C.C.(2010). An evaluation of the impact of ICT diffusion in Nigeria's higher educational system. Journal of Information Technology Impact, 10(1), 25-34.

Instiful, J., Okyere, R. F. \& Osae, S. (2003). Use of ICT for Education, Research, and Development in Ghana: Challenges, Opportunities, and Potentials. 2003 Round Table on Developing Countries Access to scientific Knowledge, The Abdusalam ICTP. Trieste. Italy.

Isaacs, S., and Hollow, D., eds. (2012). The e-Learning Africa 2012 Report. Germany: ICWE

Iwanaga, M. (2002). The Present and Future of Multimedia in Japan's Open Learning. Retrieved April 23, 2011, from http//www.ouhk.edu.hk/cridal/gdenet/Technology/technology.html

Lelliott, A., Pendlebury, S. \& Enslin, P. (2001). Online education in Africa: promises and pitfalls, South African Journal of Information Management 3(1), 1-10.

MacDougall, A. \& Squires, D. (1997). A framework for reviewing professional development programs in information technology. Journal of Information Technology, 115-126. 
Mark, J. (2002). Beyond Equal Access: Gender Equity in Learning with computers. Retrieved April 23, 2011, from http//www.edc.org/WomensEquity/pubs/digests/digest-beyond.html

Olivier, E., 2013, 'Teaching open distance learning undergraduates in theology to become effective change agents', Verbum et Ecclesia 34(1), 1-7. https://doi.org/10.4102/ve.v34i1.845

Olivier, E., 2014, 'Theological education with the help of technology,' HTS. Theological Studies 70(1), 1-7. https://doi.org/10.4102/hts.v70i1.2643

Richmond, R. (2002). Integration of Technology in the Classroom: An Instructional Perspective. SSTA Research Centre Report\#97-02. Retrieved April 23, 2011, from http://www.ssta.sk.ca/research/technology/97- 02.htm\#IBLIOGRAPHY.

Russell, T.L. (1999). The no significant difference phenomenon (5th edition).Raleigh, NC: North Carolina State University.

Sam, N. (2011). E-learning to redefine Nigeria's educational sector. Worldwide Exclusive: the complete wiki leaks cables on Nigeria.

Soderstrom, T. J, Lovqvist, J. \& Tornquist, A., 2012, 'The transformation from distance to online education: Perspectives from the educational management horizon,' The European Journal of Open, Distance, and E-Learning (1), 1-9.

Tandon, N. (1998, November). "Distance Education in the Common Wealth Countries of Asia'. Appendix to the commonwealth of Learning, Barriers to Information and Communication Technologies Encountered by Women: Summary Report. Retrieved April 23, 2011, from http://www.col.org/wdd/Barriers/CT_Asia_Report.pdf

Tinio, V. L. (2002). ICT in education, Retrieved April 23, 2011, from http://www.googler.com.ng/\#q=how+can+lCT+Expand+access+to+education\&hl=en\&biw=l 280\&bih=6 I $9 \& \mathrm{sa}=2 \& \mathrm{fp}=4193 \mathrm{~b} 342307 \mathrm{c} 5 \mathrm{~d} 2 \mathrm{~b}$ 